\title{
Assessment of the Impact of Laparoscopic Sleeve Gastrectomy on Adults Weight Reduction, Obesity-Associated Comorbidities and Quality of Life
}

\author{
Samia M. T. Osman, Assistant Professor \\ Adult Nursing, Faculty of Nursing, Assiut University \\ Hala M. M. Bayoumy, Assistant Professor \\ Adult Nursing, Faculty of Nursing, Cairo University \\ Howida K. Abdelaal, Professional Nurse \\ Staff Development Center, Assiut University Hospital
}

\begin{abstract}
Obesity a worldwide health pandemic and a growing problem among Saudi population due to inactive lifestyle, lack of physical activity and a shift to soft drink and fast food. Obesity has a negative impact on physical, social wellbeing and increased risk of impaired quality of life of people. Laparoscopic sleeve gastrectomy (LSG) is believed to be the most durable method of weight loss among obese patients improving their quality of life after this bariatric surgery is dependent on weight loss. Objective: Assess the impact of laparoscopic sleeve gastrectomy on adults' weight reduction, obesity-associated comorbidities and quality of life. Setting: The study was conducted at Surgical Department at King Fahad Hospital in Almadinuh Almunawruh, Saudi Arabia. Subjects: 100 adult patients with obesity $(B M I \geq 40 \mathrm{Kg} / \mathrm{m} 2)$ with or without obesity related comorbidities who underwent to LSG before and 12 months after surgery. Tools: Two tools were used; tool I, Socio-Demographic Characteristics \& medical data, it was developed by the researcher, tool II, Quality of Life scale to measure the impact of weight on quality of life. Results: The results revealed that, there was statistical significant weight loss, reduction in BMI ( $p<0.001)$, significant reduction in severity of comorbidities (hypertension, type 2 DM, arthritis) after surgery and significantly improved physical function, work performance and overall quality of life as well as experienced significantly lower public distress. Moreover, a significant positive correlation was shown between participants mean weight and their quality of life scores after surgery $(p=.000)$. Conclusion: The study concludes that significant reduction of patient's body weight, comorbidities and QOL post LSG. Recommendations: Application of educational program for post laparoscopic sleeve gastrectomy important for patients to improve their awareness of life style changes, especially about diet and develop a simple manual guideline of dietary modification to be available for post LSG patients and all nurses working with them.
\end{abstract}

Keywords: Laparoscopic Sleeve Gastrectomy; Weight Loss; Quality of Life; Comorbidities.

\section{Introduction}

Obesity is a worldwide public health problem that actually affects patient lifestyle, the ability of the individual performance progress. There has been a sharp increase in the prevalence of obesity in the last fifteen years around the world ${ }^{(1)}$, the World Health Organization (WHO) reported over 650 million obese adults, this means that $13 \%$ of the world's population has a Body Index Mass (BMI) $\geq 30$ $\mathrm{kg} / \mathrm{m} 2^{(2)}$. The prevalence of obesity is increasing in Saudi Arabia, affecting 30.7\% of Saudi men and $28.4 \%$ of Saudi women. This significantly high rate of obesity in Saudi Arabia is due to an inactive lifestyle, lack of physical activity and a shift to soft drink and fast food ${ }^{(3)}$.

Obesity results to serious medical complications as certain hormonedependent cancers or colon cancer, type 2 diabetes, cardiovascular disease, osteoarthritis, infertility in women, impotence in men, low self-esteem, anxiety and depression. In addition, the obesity reason for psychosocial disability and decreases quality of life (QOL) ${ }^{(4)}$ which 
refers to the overall effects of medical conditions on physical, mental, and social functioning and well-being. Many persons undergo Bariatric surgery to improve the quality of life. This change will evolve over time as weight is lost. QOL after Bariatric surgery is dependent on weight loss and impacts on general well-being ${ }^{(5)}$. Sierżantowicz (2017) added that, improving the quality of life of obese people has become a complementary objective to weight reduction ${ }^{(6)}$.

The Bariatric surgical procedure is believed to be the new era of weight reduction among obese patients. About 200,000 Bariatric procedures done worldwide each year. The goal of weight reduction surgery is not only to decrease excess weight, but also to improve comorbidities associated with obesity and quality of life (QOL) ${ }^{(7,8)}$. Schroeder (2011) reported that, Bariatric surgery increases life expectancy by an average of three years, however, a very high surgical risk may negate the potential benefit ${ }^{(9)}$.

Laparoscopic sleeve gastrectomy (LSG) has a worldwide increased indication for the surgical treatment of morbid obesity (10). The number of LSG an increasing in Saudi Arabia, and represents around eightyfive percent of obesity operation ${ }^{(3,9)}$. LGS has possible of reducing an average of 50 percent of excess body weight ${ }^{(10)}$. LSG procedure involves resection of two thirds of the stomach, including the founders, while the remaining part of the gastroesophageal junction to the pylorus along the greater curvature is used to form a sleeve, decreases the capacity of the stomach to about $100 \mathrm{ml}$, which is easier to fill and thus leads to less food eating ${ }^{(11,12)}$.

Patients underwent Bariatric surgery need a special care beyond the hospitalization period, for that the nurse requires to have knowledge, practical and interpersonal skills. Since bariatric surgery has become more prevalent in recent years to treat obesity, it is essential for the nurses to understand the procedures and how to care for this patient ${ }^{(13)}$. The nurse plays an important role before and after operation. As a matter of fact, nursing care along the continuum of the Bariatric surgical experience is key to positive outcomes for these patients and the improvement of QOL. So nursing educational support of both the patient and family (expectations for the surgery, immediate postoperative period, potential weight loss, the behaviors that lead to effective regaining of their health, guidance about lifestyle modifications, especially about a diet balanced with body requirements and changes in the overall health related quality of life (HRQL) were strictly related to the amount of weight loss) ${ }^{(11,14)}$.

\section{Significance of the study:}

Traditional treatment built on a lowcalorie regime, lifestyle modifications, increased physical activity, and medication is not always effective. The traditional method of obesity has been to view obesity just as a problem of excess weight associated with medical complications. An emerging approach is to examine weight in terms of its impact on the quality of life of an obese person. Obesity significantly influences weight-related quality of life $(\mathrm{WRQL})^{(6)}$. The QOL for people with obesity has multiple aspects that can be measured $^{(1)}$. With the increased prevalence of overweight, obesity and a number of LSG, weight-related quality of life is a worthwhile area of interest in order to begin to know the multifaceted impact of obesity management ${ }^{(4)}$. Therefore, the current study focused on assessing the effectiveness of LSG as a growing, effective approach for weight reduction targeted at improving patients' quality of life and complications associated with obesity.

\section{Aim of the Study}

The study aims to evaluate the impact of laparoscopic sleeve gastrectomy on adults' weight reduction, obesity-associated comorbidities and quality of life. 


\section{Research Hypotheses:}

1. The patients' quality of life will be improved after laparoscopic sleeve gastrectomy surgery.

2. Improvement of comorbidities associated with obesity will occur after laparoscopic sleeve gastrectomy surgery.

\section{Materials and Method}

\section{Materials}

Design: A descriptive design was utilized to fulfill the aim of this study.

Setting: Study was conducted in the Surgical Department at King Fahad Hospital, Almadinuh Almunawruh, Saudi Arabia.

Subjects: One hundred adult patients with obesity. They were diagnosed as obese, according to body mass index (BMI) $\geq 40$ $\mathrm{Kg} / \mathrm{m} 2$ with or without obesity related comorbidities, including (type 2 diabetes, hypertension, dyslipidemia, arthritis) was recruited for the study before surgery and 12 months after LSG surgery.

Inclusion Criteria: Subjects were selected according to the following criteria: age should be 18 and above with $\mathrm{BMI} \geq 40$ $\mathrm{Kg} / \mathrm{m} 2$ with / or without co-morbidity, and willing to participate in the study.

Exclusion criteria: We excluded active Helicobacter pylori infection, active gastric ulcer, GERD, previous gastric resection, pregnant women or lactating at the time of screening or at the time of surgery, younger than 18 years, older than 60 years and patients with contraindications to anesthesia administration.

\section{Tool:}

Two tools were used in this study:

\section{Tool I:}

It was developed by the researchers and consists of two parts:

Part I: Socio-demographic characteristics: to collect data related to patients' age, gender, marital status and educational level.
Part II: Clinical data: to collect data related to patients' height, weight, body mass index (BMI) and comorbid conditions (dyslipidemia, T2DM, arthritis, hypertension and sleep apnea) and lab investigations $(\mathrm{HbA} 1 \mathrm{c}$, total cholesterol and triglyceride).

\section{Tool II: Impact of Weight on Quality of} Life-Lite Scale (IWQOL-Lite)

It is a validated 31 -item, used to assess health related quality of life (HRQOL) in obese individuals, the first instrument specifically developed to assess the impact of weight on quality of life for patients undergo $\mathrm{LSG}^{(4)}$. It consists of a five sub scale (physical function 11 items, selfesteem (7 items), sexual (4 items), public distress (5 items), and 4 items related to work. Participants responded to each item using a 5-point Likert scale from 1 ("never true") to 5 ("always true") (16).

\section{Scoring system:}

Total scores for IWQOL-Lite Scale (100) are obtained by adding all items, higher scores indicate poorer quality of life on the HRQOL-Lite because items were stated in a negative direction.

Body Mass Index (BMI) classification: Normal range (18.50-24.99), Overweight $(\geq 25.00)$, and Obese $(\geq 30.00)^{(19)}$. Body Mass Index calculation, the degrees of obesity are defined by Body Mass Index calculated as weight in kilograms divided by height in meters squared), which correlates body weight to height. An internationally accepted definition of obesity is a BMI of $\geq 30 \mathrm{Kg} / \mathrm{m} 2^{(12)}$.

\section{Method}

- Ethical approval for the study conduction was granted from the ethical committee at King Fahad Hospital. Further, an official permission to conduct the proposed study was obtained from the Director of King Fahad Hospital.

- An Impact of Weight on Quality of Life-Lite (IWQOL-Lite) Scale was 
translating into Arabic by the researchers to ensure consistency and inter-rater reliability ${ }^{(18)}$. The content validity of the translated tool was checked and revised by 3 professors who are experts in nursing and medical field.

- Study tools were revised by jury to ensure the content validity, the jury consisted of 3 experts in medical surgical nursing and Bariatric surgery.

- The pilot study was carried out on 10 patients to test the applicability of the tool and those numbers of patients were excluded from the study.

- After securing participants approval and consent, data collection process started. Socio-demographic information, comorbidities, preoperative anthropometric parameters (height, weight, BMI), blood pressure, QOL Scale (domains) were obtained from the participants by the researchers through a structured interview from outpatient clinic of surgery using tools I \& II within 30 min, also the included participants were basically subjected to full laboratory investigations (blood glucose, HbA1c, total cholesterol, triglyceride), abdominal ultrasonography, before surgery as hospital routine. Data related to participants' postoperative quality of life, comorbidities and anthropometric parameters were reassessed once after 12 months from surgical treatment by using the same tools, tool I part II and tool II (QOL) through a structured interview during patient's follow up in outpatient clinic of surgery and to assess comorbidities improvement, in cases of arthritis, subjectively reported by the patient and objectively in cases of DM type $2 \&$ dyslipidemia by obtaining blood sample for analysis (HbA1c, total cholesterol and triglyceride) and hypertension by measuring blood pressure.

- Data collection was carried out between January 2014 to November 2016 .

\section{Ethical considerations:}

1. Verbal consent from the patient to participate in the study was obtained.

2. Study aim was explained and they were assured of the confidentiality, privacy and anonymity of their responses. They were informed that their participation is voluntary and that they can withdraw at any time.

\section{Statistical Analysis}

Data were collected and fed to statistical package of social sciences (SPSS) version 20. All statistical analysis was done using 2 tailed tests and $\mathrm{p}$ value less than or equal 0.05 was considered to be statistically significant. Descriptive statistics including percentage and frequencies which was used for categorical data, continuous data are represented as means \pm SD. Pearson's coefficient was employed to test the correlation between outcome variables.

\section{Results}

Participants' Characteristics $(\mathrm{n}=100)$ are described in table 1 . Most of the participants (49\%) had an age range between 25 to $<35$ years. More than half of the participants were males, and almost two third of them $79 \%$ had university education and $71 \%$ had comorbidities ranged between hypertension, arthritis, diabetes and dyslipidemia.

Table (2) illustrates participant's weight, height and BMI pre and after Laparoscopic sleeve gastrectomy. There was statistically significant difference between participants' preoperative and postoperative weight and BMI at $\mathrm{p}<0.05$. The mean BMI decreased from $46.78 \pm 7.73$ to $30.56 \pm 7.53 \mathrm{~kg} / \mathrm{m} 212$ months after surgery. Also the participants mean weight decreased from $126.38 \pm 24.97$ 
to $81.41 \pm 20.87$. The difference is statistically significant.

Table (3) shows the mean scores of HbA1c, total cholesterol, triglyceride, and blood pressure before and after laparoscopic sleeve gastrectomy. A significant reduction in severity of comorbidities was observed after LSG surgery $\mathrm{p} \leq 0.05$.

Table (4) illustrates the distribution of obesity-associated comorbidities before and after laparoscopic sleeve gastrectomy. The percentages of patients with hypertension (10\%), hyperlipidemia (13\%), diabetes mellitus type $2(13 \%)$ and arthritis (20\%), were significantly reduced to $3 \%, 4 \%$ and $5 \%$ respectively.

Table (5) and figure (1) shows HRQOL domains mean score distribution both at before and after Laparoscopic sleeve gastrectomy and significant statistical differences in HRQOL domains (physical function, public distress, and work in addition to overall HRQOL among the study participants before and after LGS surgery at $\mathrm{P} \leq 0.05$.

Table (6) shows a significant weak positive correlation between participants mean weight scores and their total mean score for quality of life after laparoscopic sleeve gastrectomy surgery $r=.34$ at $\mathrm{P}<0.05$.

Figure (2) shows BMI spread along different weight categories after surgery. At pre-operative period $100 \%$ of participants were categorized as obese as compared to only $41 \%$ after surgery.

\section{Discussion}

Bariatric surgery approved to be effective in providing weight loss of large magnitude, correction of comorbidities and excellent short-term and long-term outcomes, decreasing overall mortality and providing an improved survival rate with better quality of life ${ }^{(12,20)}$. LSG is a new bariatric procedure reported. Several reports indicate that the LSG is an effective weight loss surgical procedure without surgical and nutritional complications associated with other types of weight loss procedures ${ }^{(7)}$.
The current study shows that most of the participants were between the age group $26<35$ years. This result agreed with Charalampakis et al. (2015), who reported that, most of the patient undergo LSG were between age group $(20-56)^{(21)}$, and the study result shows, more than half of the participants were males, this finding agree with Aldaqal (2013), result which reported that, the prevalence of obesity in Saudi Arabia in men were more than women ${ }^{(3)}$, but in other studies carried by Sammour (2010), Fezzi et al. (2011), D'hondt et al. (2011) and Alley et al. (2012), shows more in female than in male. Also revealed that, about two third of participants were married, this result agreed with Brunault et al. (2011) who stated that, $(75.9 \%)$ of the patients with LSG were married ${ }^{(7,22-25)}$.

The results of this study underlined that, the LSG is an effective procedure in reducing weight, where all participants were obese before surgery whereas after surgery, about two third of them their weight and BMI reduced. This finding agree with Major (2015) who stated that, bariatric surgery represents the only effective treatment for obesity leads to significant, long-term weight loss and significant body mass reduction with a concomitant significant improvement in overall quality of life. Also one third of the participants gotten a normal weight and BMI after LSG operation $^{(26)}$.

Regarding the comorbidities, the result of the present study revealed that, significant reduction in severity of comorbidities was also observed after 12 months of LSG operation. These parameters changed significantly. This finding supported by Major et al. (2015), Albanopoulos et al. (2016) and Shimizu et al. $(2016)^{(26-28)}$.

Diabetes significantly improved after surgery, during the preoperative evaluation, 10 patients $(10 \%)$ had T2DM, half of them decreased their antidiabetic medication dose and $5 \%$ of these 10 patients completely discontinued antidiabetic medication after surgery, this finding is in line with previous 
studies demonstrating that diabetes resolution occurs in $66-80 \%$ of patients undergoing LSG .After the operation, the improving effect of LSG onT2DM within a short time may be explained by poorly predigested food, which is directly transiting from the sleeve to the distal bowel, improves glucose metabolism by stimulating intestinal cells to secrete glucagon like peptide 1 (GLP 1) and LSG mechanism of action that decreased $\mathrm{HCl}$ production may innervate antrum to produce gastrin releasing peptide that is responsible for early phase secretion of GLP $^{(29)}$.

Also, hypertension was present in 10 patients, $6 \%$ of these 10 patients completely discontinued antihypertensive medication, and the dose of medication was decreased in $4 \%$ of them this finding supported by Sjostrom et al. (2014), Dalbeth et al. (2014), Santos et al. (2014), Shimizu (2015) and stated that, Bariatric surgery lead to substantial weight loss that has been associated with improvement, sometimes remission of chronic illness such as diabetes mellitus, hypertension and arthritis and reductions in medication use $\mathrm{e}^{(28,30-32)}$.

Moreover, the participants reported significant improvements in several domains of weight-related quality of life following LGS operation this finding supported by (Sarwer et al. 2010 \& Mohos et al. 2010) who found that, after one and two years following LSG, significant improvement in physical, psychosocial and sexual functioning domains ${ }^{(33,34)}$.

As regards quality of life of the participants, by using specific quality of life questionnaire, the present study showed that, "physical activity" dimension in the IWQOL shows an improvement after operation. The weight reduction facilitates the movement by decreasing the handicap caused by the weight and the resumption of normal physical activities, moreover decrease of the "physical pains" contributes to a more freedom of movement. This result agrees with Fezzi et al. (2011) who stated that, the physical function, having the biggest variation after LSG operation ${ }^{(22)}$.

The result of the present study also revealed that, sexual life aspect has the weakest score before the operation and evolves positively after the operation. The weight reduction and the increase of the self-esteem are the criteria which can explain the good results having noticed an improvement in its sexual life. This result agrees with Batsis et al. (2009) who stated that, self-esteem has the weakest score in preoperative quality of life and positive improvement after the surgery in the majority of the population. The transformation of the body towards a refinement delights the operated person who appropriates a new image of himself and numerous patients characterize their new state of a "second life". Also the present study showed, an important variation of the scores of the "public distress" dimension in the HRQOL. The loss of weight decreases the mockeries and the discriminations of the other person towards obese patients. The improvement of self-esteem also explains a return towards others after acceptance of own ${ }^{(35)}$.

In the same line with the present study finding by Barefoot et al. (2012), Lakdawaia et al. (2010) and Mohs et al. (2010) they reported that, improvement of QOL is well documented following $\mathrm{LSG}^{(8,11,34)}$. Also, Major (2015) added that in a follow-up study showed that, significant improvement of HR-QOL after operation and the peak improvement was located between 6 months and 1 year after surgery. Additionally, in the present study there was a weak positive correlation between BMI and the IWQOL-Lite total scores, which mean that, when BMI decrease lead to decrease of QOL impairment due to obesity as which in turn improve overall QOL. The current result provides evidence for the association between weight and quality of life. This finding is consistent with the finding of the previous studies by Mohs et al. (2010) who 
reported that, obesity is associated with impairment of $\mathrm{QOl}^{(26)}$.

\section{Conclusion}

Based on the finding of the present study, it can be concluded that Laparoscopic Sleeve Gastrectomy leads to improvement of patient's quality of life, the long term improvements are positively associated with long term amount of weight reduction.

Significant reduction in severity of comorbidities associated with obesity after LGS was also found. Moreover, after LGS surgery a statistical significant positive correlation was found between weight reduction and patients' improvement of quality of life.

\section{Recommendations}

- Development and application of educational session for post Laparoscopic Sleeve Gastrectomy patients to improve their understanding about the importance of lifestyle changes and modification, especially about diet.

- Develop a simple manual guideline of dietary modification to be available for post Laparoscopic Sleeve Gastrectomy patients and all nurses working with them. 
Table (1): Socio-demographic characteristics of the participants $(n=100)$

\begin{tabular}{|l|c|c|}
\hline \hline Characteristics & No. & $\%$ \\
\hline Age (in years) & \multicolumn{2}{|c||}{} \\
$18<25$ Years & 18 & 18.0 \\
$25<35$ & 49 & 49.0 \\
$35<45$ & 29 & 29.0 \\
$45 \leq 55$ & 4 & 4.0 \\
\hline M SD & \multicolumn{2}{|c|}{$33.2 \pm 2.3$} \\
\hline Gender & 55 & 55.0 \\
Male & 45 & 45.0 \\
Female & \multicolumn{2}{|c|}{} \\
\hline Educational level & 1 & 1.0 \\
Primary level & 5 & 5.0 \\
Intermediate & 15 & 15.0 \\
High school & 79 & 79.0 \\
University & & \\
\hline Marital Status & 65 & 65.0 \\
Married & 25 & 25.0 \\
Single & 10 & 10.0 \\
Divorced & & \\
\hline
\end{tabular}

Table (2): Participants' mean weight, height and BMI before and after laparoscopic sleeve gastrectomy $(n=100)$

\begin{tabular}{||l|c|c|c|}
\hline & $\begin{array}{c}\text { Before surgery } \\
\text { M } \pm \text { SD }\end{array}$ & $\begin{array}{c}\text { After surgery } \\
\text { M } \pm \text { SD }\end{array}$ & p \\
\hline Weight & $126.38 \pm 24.97$ & $81.41 \pm 20.87$ & $.000^{*}$ \\
\hline Height & $164.42 \pm 9.14$ & $164.42 \pm 9.14$ & - \\
\hline BMI & $46.78 \pm 7.73$ & $30.56 \pm 7.53$ & $.000^{*}$ \\
\hline
\end{tabular}

$B M I=$ body mass index

$* P \leq 0.05$

Table (3): Mean scores of Hb1AC, cholesterol, triglyceride, and blood pressure before and after laparoscopic sleeve gastrectomy $(n=100)$

\begin{tabular}{|l|c|c|c||}
\hline Comorbidities & $\begin{array}{c}\text { Before surgery } \\
\mathbf{M} \pm \text { SD }\end{array}$ & $\begin{array}{c}\text { After surgery } \\
\mathbf{M} \pm \text { SD }\end{array}$ & $\mathbf{p}$ \\
\hline Hb1AC & $8.13 \pm 0.1698 .9$ & $6.2 \pm 1.33$ & $.002^{*}$ \\
\hline Cholesterol, & $293.3 \pm 2.7$ & $195.1 \pm 0.3 .2$ & $.000^{*}$ \\
\hline Triglyceride & $193.30 \pm 2.3$ & $130.4 \pm 2.5$ & $.003^{*}$ \\
\hline Blood pressure & $150.5 \pm 685.1$ & $116.5 \pm 4.7$ & .000 \\
\hline
\end{tabular}

$* P \leq 0.05$ 
Table (4): Distribution of obesity-associated comorbidities before and after laparoscopic sleeve gastrectomy $(n=100)$

\begin{tabular}{|l|c|c|c||}
\hline \multirow{2}{*}{ Comorbidities } & \multirow{2}{*}{$\begin{array}{c}\text { Before surgery } \\
\text { NO \% }\end{array}$} & \multicolumn{2}{|c|}{$\begin{array}{c}\text { After surgery } \\
\text { NO \% }\end{array}$} \\
\cline { 3 - 4 } & & $\begin{array}{c}\text { Discontinuation of } \\
\text { Medication }\end{array}$ & $\begin{array}{c}\text { Reduction of } \\
\text { medication dose }\end{array}$ \\
\hline T2DM & $13(13 \%)$ & $5(5)$ & $8(8 \%)$ \\
\hline Arthritis & $20(20 \%)$ & - & $20(20 \%)$ \\
\hline Hypertension & $10(10 \%)$ & $6(6 \%)$ & $4(4 \%)$ \\
\hline Sleep apnea & $15(15 \%)$ & $9(9 \%)$ & $6(6 \%)$ \\
\hline Dyslipidemia & $13(13 \%)$ & $10(10 \%)$ & $3(3 \%)$ \\
\hline
\end{tabular}

T2DM: type 2 diabetes mellitus

Table (5): Health related quality of life domains (HRQOL) before and after laparoscopic sleeve gastrectomy among the participant patients

\begin{tabular}{|l|c|c|c|}
\hline \hline IWQOL Domains & $\begin{array}{c}\text { IWQOL Before surgery } \\
\mathbf{M} \pm \text { SD }\end{array}$ & $\begin{array}{c}\text { IWQOL After surgery } \\
\mathbf{M} \pm \text { SD }\end{array}$ & $\mathbf{p}$ \\
\hline Physical Function & $40.0 \pm 8.9$ & $16.5 \pm 5.8$ & .007 \\
\hline Self Esteem & $26.1 \pm 6.6$ & $10.1 \pm 3.8$ & .290 \\
\hline Sexual life & $14.3 \pm 4.3$ & $5.4 \pm 2.5$ & .376 \\
\hline Public distress & $17.1 \pm 5.1$ & $6.3 \pm 2.5$ & .055 \\
\hline Work & $11.2 \pm 4.6$ & $5.1 \pm 2.1$ & $.000^{*}$ \\
\hline IWQOL overall & $90.2 \pm 21.7$ & $43.2 \pm 11.9$ & $.000^{*}$ \\
\hline
\end{tabular}

$* P \leq 0.05$

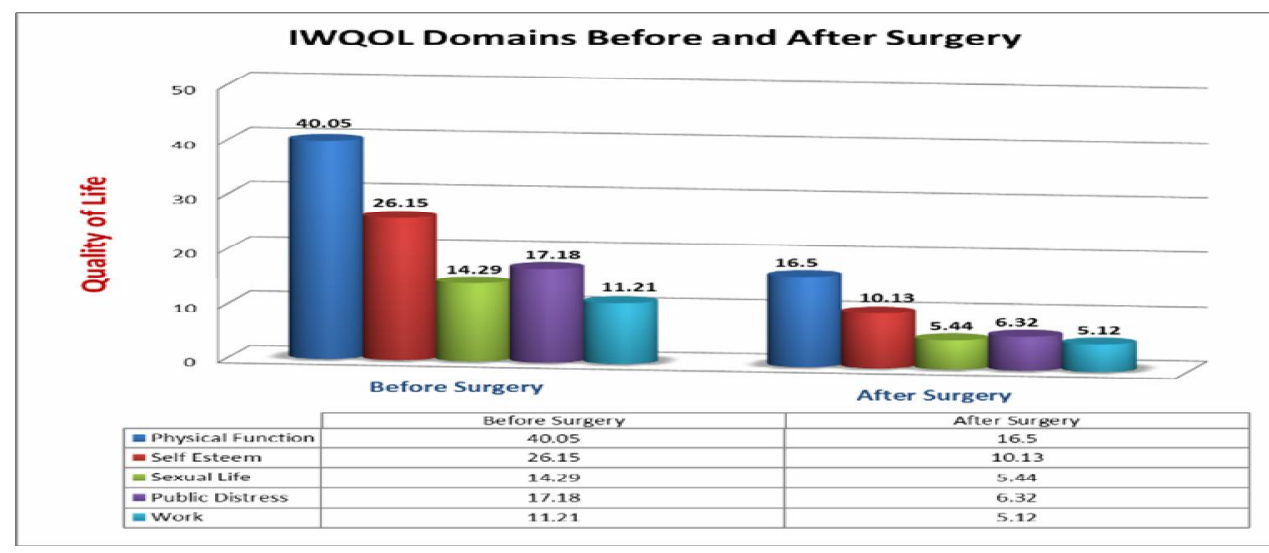

Figure (1): Distribution of quality of life Domains mean scores before and after laparoscopic sleeve gastrectomy surgery 
Table (6): Correlation between weight and total quality of life (HRQOL) items after laparoscopic sleeve gastrectomy surgery

\begin{tabular}{||c|c|c||}
\hline \hline Items & QOL & p \\
\hline \multirow{2}{*}{ Weight } & $\mathbf{r}$. & $.000^{*}$ \\
\cline { 2 - 2 } & $.34 *$ & \\
\hline
\end{tabular}

$* P \leq 0.05$

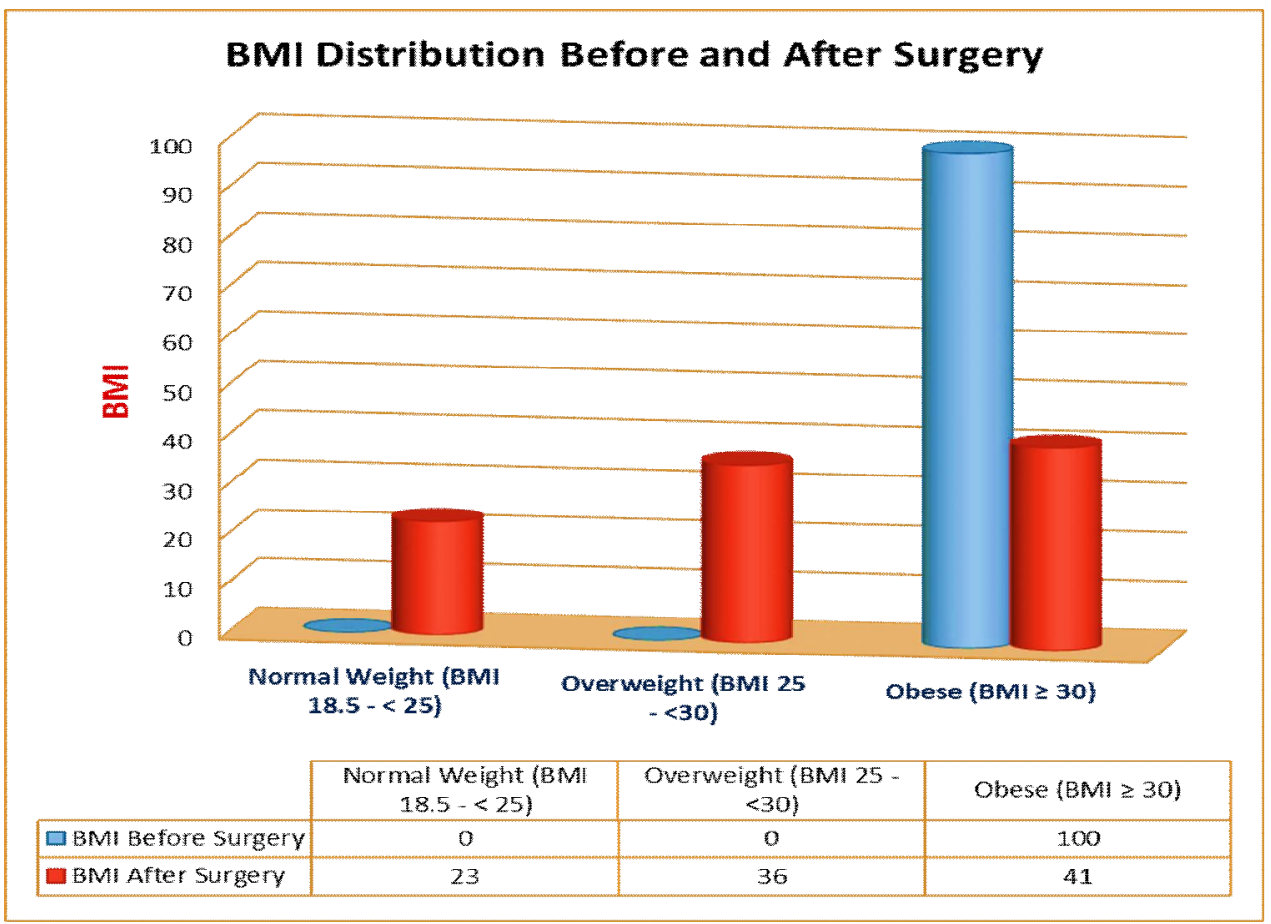

Figure (2): Distribution of participants BMI before and after laparoscopic sleeve gastrectomy surgery 


\section{References}

1. Tessier A, Zavorsky G, Carli F and Mayo N. Understanding the Determinants of WeightRelated Quality of Life among Bariatric Surgery Candidates. Journal of Obesity. 2012; 9 .

2. World Health Organization. Obesity and overweight fact sheet.2016.

3. Aldaqal S M and Sehlo M.G. Self-esteem and quality of life in adolescents with extreme obesity in Saudi Arabia: the effect of weight loss after laparoscopic sleeve gastrectomy. General hospital psychiatry, 2013; 35(3):259-264.

4. Cox, T. Examining the association between body mass index and weight related quality of life in black and white women. Doctor of Philosophy. Alabama. 2010.

5. Hachem A and Brennan L. Quality of life outcomes of bariatric surgery: a systematic review. Obes Surg. 2016; 26 (2):395-409.

6. Sierżantowicz $\mathrm{R}$ et al. Effect of BMI on quality of life and depression levels after bariatric surgery. Adv Clin Exp Med. 2017; ISSN 1899-5276.

7. Sammour T, Hill AG, Singh $P$, Ranasinghe A, Babor R and Rahman, H. Laparoscopic sleeve gastrectomy as a single-stage bariatric procedure. Obes Surg. 2010; 20:271-275.

8. Lakdawaia MA, Bhasker A, Mulchandani D, Goel S and Jain S. Comparison between the results of laparoscopic sleeve gastrectomy and laparoscopic gastric bypass in the Indian population: a retrospective 1-year study. Obes Surg. 2010; 20:1-6.

9. Schroeder R, Garrison JM and Johnson MS. Treatment of Adult Obesity with Bariatric Surgery. Am Fam Physician. 2011; 84(7):805-814.

10. Ramos AC, Bastos S, Ramos MG, Bertin TS, Galvão TD, Lucena $\mathrm{J}$ and Campos $\mathrm{M}$. Medium-term follow-up results with laparoscopic sleeve gastrectomy. ABCD Arq Bras Cir Dig. 2015; 28(Supl.1):61-64.

11. Barefoot LC and Nadler EP. Nursing Care of the Adolescent Patient Undergoing
Laparoscopic Sleeve Gastrectomy. Bariatric Nursing and Surgical Patient Care.2012; 7(3):116-120.

12. Hassan AM, Hussein AM and Balamoun HA. Comparison of Comorbidity Resolution and Improvement between Laparoscopic Sleeve Gastrectomy and Laparoscopic Adjustable Gastric Banding. Med. J. Cairo Univ., 2016;84(1): 1219-1225.

13. Ponstein L. Assessing the Nurses' Knowledge of Bariatric Surgery: Performance Improvement Project Bariatric Nursing and Surgical Patient Care. December 2012;7(4):167-171

14. Steyer NH, Oliveira MC, Gouvêa MR, Echer IC and Lucena SN. Clinical profile, nursing diagnoses and nursing care for postoperative bariatric surgery patients. 2016; 37(1):19831447.

15. Snyder-Marlow G, Taylor D and Lenhard JM. Nutrition care for patients undergoing laparoscopic sleeve gastrectomy for weight Loss. J Am Diet Assoc.2010; 110:600-607.

16. Kolotkin RL and Crosby RD. Psychometric evaluation of the impact of weight on quality of life-lite questionnaire (IWQOL-lite) in a community sample. Qual Life Res. 2002; 11(2):157-71.

17. Canetti L, Berry EM and Elizur Y. Psychosocial predictors of weight loss and psychological adjustment following bariatric surgery and a weight-loss program: the medicating role of emotional eating. Int $\mathrm{J}$ Eat Disord. 2009; 42:109-117.

18. Zaidi U, Awad SS, Mortada EM, Qasem HD and Fahad G. psychometric evaluation of Arabic version of self-esteem, psychological well-being and impact of weight on quality of life questionnaire (iwqol-lite) in female student sample of pnu. 2015; 8 (2).

19. World Health Organization. Obesity: preventing and managing the global epidemic. WHO technical Report Series 2000; 894.

20. Zhou D, Jiang X, Ding W, Zhang D, Yang L and Zhen $\mathrm{C}$, et al. Impact of bariatric surgery on ghrelin and obestatin levels in obesity or 
type 2 diabetes mellitus rat model. J Diabetes Res.2014; 569435.

21. Charalampakis V, Bertsias G, Lamprou V, de Bree E, Romanos J and Melissas J. Quality of life before and after laparoscopic sleeve gastrectomy. A prospective cohort study. Surgery for Obesity and Related Diseases, 2015; 11(1): 70-76.

22. Fezzi M, Kolotkin RL, Nedelcu M, Jaussent $\mathrm{A}$ and Schaub $\mathrm{R}$ et al. Improvement in Quality of life after laparoscopic sleeve gastrectomy. Obes Surg. 2011; 21:11611167.

23. D'hondt M, Vanneste S, Pottel H, Devriendt $\mathrm{D}$ and Van Rooy $\mathrm{F}$ et al. Laparoscopic sleeve gastrectomy as a single stage procedure for the treatment of morbid obesity and the resulting quality of life, resolution of comorbidities, food tolerance, and 6-year weight loss. Surg Endosc. 2011; 25:24982504

24. Alley JB, Fenton SJ, Harnisch MC, Tapper DN and Pfluke JM et al. Comparison of Comorbidity Resolution and Improvement between Laparoscopic Sleeve Gastrectomy and Laparoscopic Adjustable Gastric Banding Surg Obes Relat Dis. 2016;31-40.

25. Brunault P, Jacobi D, Leger J, BourbaoTournois $\mathrm{C}$ and Huten $\mathrm{N}$ et al. Observations regarding 'quality of life' and 'comfort with food' after bariatric surgery: comparison between laparoscopic adjustable gastric banding and sleeve gastrectomy. Obes Surg. 2011; 21:1225-1231.

26. Major $P$, Matłok $M$, Pędziwiatr $M$, Migaczewski M, Budzyński P, Stanek M, Michał K, Natkaniec M, and Budzyński A. Quality of Life After Bariatric. Surgery Obes Surg. 2015; 25(9): 1703-1710.

27. Albanopoulos K, Tsamis D, Natoudi M, Alevizos L, Zografos G and Leandros E1. Surg Endosc. The impact of laparoscopic sleeve gastrectomy on weight loss and obesity-associated comorbidities: the results of 3 years of follow-up. 2016; 30(2):699705 .
28. Shimizu H, Hatao F, Imamura $\mathrm{K}$, and Takanishi k. Early effects of sleeve gastrectomy on rheumatoid arthritis. 2015; Published by Elsevier Inc.

29. Nosso GL. Angrisani G. Saldalamacchia PP, Cutolo M. Cotugno R, Lupoli, G. and Capaldo B. Impact of Sleeve Gastrectomy on Weight Loss, Glucose Homeostasis, and Comorbidities in Severely Obese Type 2 Diabetic Subjects. Journal of Obesity. 2011; 4.

30. Sjostrom L, Peltonen M, Jacobson P, Ahlin $\mathrm{S}$, Andersson-Assarsson $\mathrm{J}$ and Anveden $\mathrm{A}$ et al. Association of bariatric surgery with long-term remission of type 2 diabetes and with microvascular and macrovascular complications. JAMA. 2014; 311(22): 2297304.

31. Dalbeth N, Chen P, White M, Gamble GD, Barratt-Boyes $C$ and Gow PJ et al. Impact of bariatric surgery on serum urate targets in people with morbid obesity and diabetes: a prospective longitudinal study. Ann Rheum Dis. 2014; 73(5):797-802.

32. Santos J, Salgado P, Santos C, Mendes P, Saavedra $\mathrm{J}$ and Baldaque $\mathrm{P}$ et al. Effect of bariatric surgery on weight loss, inflammation, iron metabolism, and lipid profile. Scand J Surg. 2014; 103(1):21-5.

33. Sarwer DB, Wadden TA, Moore RH, Eisenberg MH and Raper SE, Gastric Bypass Surgery. Surg Obes Relat Dis 2010; 6, 60814.

34. Mohos E, Schmaldienst E and Prager M. Quality of life parameters, weight change and improvement of co-morbidities after laparoscopic and roux $\mathrm{Y}$ gastric bypass and laparoscopic gastric sleeve resectioncomparative study. Obes Surg. 2010; 14.

35. Batsis JA, Lopez-Jimenez F and CollazoClavell ML et al. Quality of life after bariatric surgery: a population-based cohort study. Am J Med. 2009; 122(11):1055 -1051. 